\title{
EPIDEMIOLOGY OF MALIGNANT TUMORS OF THE RESPIRATORY ORGANS IN THE TRANSCARPATHIAN REGION DURING 2015-2019
}

DOI: 10.36740/WLek202105132

\author{
Olga V. Feger, Renata Yu. Pohoriliak \\ UZHHOROD NATIONAL UNIVERSITY, UZHHOROD, UKRAINE
}

\begin{abstract}
The aim: Study and analysis of the epidemiological situation of malignant neoplasms of the respiratory system at the regional level during 2015-2019. Materials and methods: The study was based on the analysis of data from the state statistical reporting (forms №7, №35 - healthy) and the database of the National Cancer Registry during 2015 - 2019, which was approved by the conclusion of the bioethics commission of Uzhhorod National University (protocol №2/2 of 15.02.2021).

Conclusions: The study found an increase in the level of malignant neoplasms of the respiratory system by $17,28 \%$, as well as the uprise in the proportion of malignant neoplasms of the respiratory system in the structure of all tumours, by $11,98 \%$; detection of malignant neoplasms of the respiratory organs in the late stages; the predominance of the death rate of men from MT over women, as well as mortality rate of the respiratory organs MT up to 1 year from the moment of diagnosis among men is higher over women.
\end{abstract}

KEY WORDS: malignant neoplasms, respiratory organs, morbidity, mortality

Wiad Lek. 2021;74(5):1219-1221

\section{INTRODUCTION}

Malignant neoplasms are the most important medical and biological problem for Ukraine and most countries overall. Socio-economic significance of the problem is since cancer reduces the life expectancy of the male population of Ukraine by 3,6 years, and female, by 2,5. The life expectancy of patients with oncopathology decreases by 17-18 years and is up to $40 \%$ of that period for working age. In Ukraine, the number of patients with malignant neoplasms of the respiratory system per year exceeds 16 thousand. Most lung cancer patients die within a year of diagnosis [1].

Lung cancer is most commonly diagnosed among all malignancies and is the leading cause of cancer death worldwide [2].

Lung tumour is the leading cause of cancer mortality worldwide, exceeding prostate, breast and colon cancer mortality combined [3]. However, it has one of the worst survival outcomes of all malignancies, as the vast majority of patients get diagnosed in the later stages when surgery or other treatments are less effective [4].

A national lung screening study has shown that low-dose computed tomography screening for lung cancer reduces mortality by $20 \%$ [5]. In practice, the success of any lung cancer screening program will depend on the efficient identification of high-risk individuals. Risk prediction models have been recognized as a method of identifying individuals at high risk of developing lung cancer [6].

Research suggests that there is a link between previous respiratory illnesses (ARIs), including chronic bronchitis, emphysema, tuberculosis, pneumonia, and a diagnosis of lung cancer [7].
Tobacco is a common risk factor for STDs and lung cancer. However, the mechanisms of PRP independent affection on the risk of lung cancer are insufficiently studied, but it is hypothesized that inflammation caused by PRP may act as a catalyst in lung tumours development [8].

The results of international lung cancer cases consortium (SYNERGY project) show that comorbid respiratory diseases such as chronic bronchitis and emphysema, continue to be positively associated with lung cancer [9].

Identifying high-risk individuals will facilitate early diagnosis, reduce overall costs, and improve current poor lung cancer survival [10].

In Ukraine, malignant neoplasms of the respiratory organs (larynx, trachea, bronchi and lungs, pleura) occupy the first place in the structure of morbidity of workers with occupational cancer (78.2\%). Among them, bronchial and pulmonary diseases predominate $(90,4 \%)$. The average age of the primary establishment of PR of respiratory organs is (years): pleura - 55,3 $\pm 13,5$; larynx $-57,9 \pm 9,7$; bronchi and lungs - 60,1 $\pm 9,2[11]$.

\section{THE AIM}

To study and analyze the state of the epidemiological situation of malignant neoplasms of the respiratory system in the Transcarpathian region during 2015-2019.

\section{MATERIALS AND METHODS}

The data of the state statistical reporting (forms №7, №35) and the database of the National Cancer Registry in the dynamics 
for 2015-2019 were analyzed. The research methodology involved the use of a set of following methods: medical-statistical, epidemiological and bibliosemantic, which was approved by the conclusion of the bioethics commission of Uzhhorod National University (protocol №2/2 of 15.02.2021).

\section{REVIEW AND DISCUSSION}

An urgent problem of modern medicine is malignant neoplasms (MN) of man, which in the general structure of mortality of the population of most countries on earth takes the 2nd-3rd place [12]. According to the study, it was found that the level of primary incidence of malignant neoplasms in the period from 2014 to 2019 increased by $5,55 \%$. Regarding malignant neoplasms of the respiratory system, there was also a tendency for the level increase by $17,28 \%$ during that period. The incidence of laryngeal oncopathology during the study period decreased by $13,81 \%$, while the level of malignant neoplasms of the trachea, bronchi and lungs increased by $23,80 \%$.

During the study period, the proportion of patients diagnosed with malignant neoplasms, in general, decreased by $26.83 \%$ during preventive examinations, and the proportion of detected malignant neoplasms of the trachea, bronchi and lungs during preventive examinations ranged from $3,00 \%$ to $3,50 \%$.

The share of malignant neoplasms of the respiratory system in the structure of all malignant neoplasms ranged from $10,59 \%$ in 2018 to $13,08 \%$ in 2017 and increased by $11,98 \%$. Thus, in 2015 the of laryngeal oncopathology was $1,84 \%$, and in $2019-1,48 \%$, which is $19,47 \%$ less than in 2015. The proportion of tracheal, bronchial and lung cancer cases during the study period increased by $17,15 \%$ (in 2015 it was $9,35 \%$, and in $2019-10,95 \%$ ), but the proportion of laryngeal cancer decreased by $19,47 \%$. The percentage of cases of malignant neoplasms of the respiratory organs detected during preventive examinations, increased by $38,5 \%$ (2015 - 2,62\%, $2019-3,63 \%)$.

When studying the proportion of patients with a newly diagnosed malignant neoplasm of the respiratory system, depending on the stage of the disease, the following trends were found: the largest group are patients with stage IV disease, ranges from $41,71 \%$ in 2019 to 51,00 and $76,00 \%$ in 2018. The second place is taken by patients diagnosed with stage III respiratory neoplasms (31,19\% -35,89\%), and the lowest percentage of patients diagnosed with stage I-II disease (16,39\% - 23,72\%). Studying the proportion of patients with a newly diagnosed laryngeal cancer, it was found that the largest target is patients with stage III disease (from $44,68 \%$ in 2018 to $71,43 \%$ in 2015), while for malignant neoplasms of the trachea, bronchi and lungs the first place is taken by patients with stage IV disease and ranges from $39,89 \%$ in 2016 to $56,31 \%$ in 2018 . Next, are patients diagnosed at the I-II stage of the disease $(18,37 \%$ - 42,50\%), for the trachea, bronchi and lungs - at the III stage $(25,94 \%-32,90 \%)$. The last place for laryngeal cancer are patients diagnosed with stage IV $(10,00 \%$ in 2019 to $23,40 \%$ in 2018), for tracheal, bronchial and lung cancer - in stages I-II (from 16,00\% in 2015 to $21,29 \%$ in 2019).
The 5-year survival of patients with laryngeal cancer in 2015 was 1,56\%o, and in 2019 - 1,62\%o (during the study period, the figure increased by $3,80 \%$ ), in turn, survival for 5 years or more in patients with cancer of the trachea, bronchi and lungs in 2015 amounted to $2,57 \%$ and increased to $2,85 \%$ in 2019 , which reflects an increase of $10,80 \%$. In general, the level of 5-year survival of respiratory tract infections increased by $8,23 \%$ (from 4,13\%o in 2015 to $4,47 \%$ in 2019 ).

During the study period, at the regional level, the frequency of deaths of men from MT exceeds the frequency among women, although among women the level increased by $16,38 \%$ within 5 years. It was found that the level of deaths of men from respiratory disease is much higher (from 3,95 $\%$ in 2019 to $4,69 \%$ in 2016), while in women this figure ranges from 0,55 (in 2015 to $0,78 \%$ in 2018 . However, during the study period, the level of respiratory failure among men decreased by $4,78 \%$, among women - increased by $31,09 \%$. Regarding localization, the mortality rate from laryngeal malignancies among women is lower than among men and ranges from $0,00 \%$ in 2016 to $0,06 \%$ in 2018 . The frequency of deaths from TN of the trachea, bronchi and lungs among women increased from $0,54 \%$ in 2015 and 2017 to $0,72 \%$ o in 2018 , ie by $31,96 \%$, while among men it is $3,52-4,14 \%$.

If we analyze the proportion of respiratory deaths from MT in the structure of total mortality from MT, the following trend is revealed. Mortality from the respiratory disease has a different trend and ranges from $30,77 \%$ in 2019 to $32,56 \%$ in 2018 .

In general, the study found that the level of deaths from MT up to 1 year from the date of diagnosis among men is higher than among women. The same tendency is confirmed also about MT of respiratory organs. During the study period, the death rate before the age of 1 year among men decreased by $15,94 \%$, and among women increased by $64,19 \%$. The frequency of the number of patients with laryngeal cancer who received special treatment in the dynamics from 2015 to 2019, both in general and among the first registered decreased by $22,56 \%$ and $14,10 \%$, respectively. The level of patients with oncopathology of the trachea, bronchi, lungs who received special treatment increased by $54,75 \%$ in total and among those first detected by $74,74 \%$, which confirms the tendency to decrease the incidence of laryngeal fibroids and increase the incidence of tracheal fibroids, bronchi and lungs.

In general, during the study period, special treatment among patients with the respiratory disease increased by $29,49 \%$, and among newly registered - by $43,65 \%$. Among patients with respiratory diseases who receive special treatment, the first place is occupied by the chemotherapeutic method, the second - the chemoradiation method, the third - the combined or complex method, the fourth-place - the radiological and the fifth - surgical. In the dynamics of 5 years, the proportion of patients who received surgical treatment of respiratory disease increased by $23,70 \%$, chemotherapy - by $26,39 \%$, radiation and combined - 1,56 and 1,33 times, respectively, while the proportion of patients who received chemoradiation treatment decreased by $31,40 \%$.

Concerning localization, among patients with laryngeal 
MT special treatment is mainly combined or chemoradiation. There is a tendency to increase the use of such methods as surgical (2,2 times), radiation (by 10,84\%) and combined, or complex (by $94,17 \%$ ), as well as reducing the use of chemotherapy (by 35,31\%) and chemoradiation (by $22,36 \%$ ). A special treatment of trachea MT, bronchial tubes and lungs chemotherapeutic and combined methods of treatment prevail. There is an increase in the use of radiation (by $5,68 \%$ ), chemotherapy (by $8,44 \%$ ), combined or complex (by $78,12 \%$ ) and a decrease in surgery (by 5,33\%), chemoradiation (by $53,79 \%$ ) methods.

The percentage of respiratory disorders in the structure of respiratory organs in general among the population of the region is $12,24 \%-13,77 \%$ and for 5 years increased by $7,82 \%$. The share of the respiratory tract is higher among men and increased by $9,37 \%$, and among women by $4,72 \%$.

Further research will be aimed at studying the characteristics of the risk factors for the development of malignant neoplasms of the respiratory system, the assessment of patients' availability and quality of care for respiratory disorders, etc., which in the future will help to scientifically substantiate and develop an optimized model at the present stage.

\section{CONCLUSIONS}

1. The study found: 1 . Increase in the level of malignant neoplasms of the respiratory system for 5 years by $17,28 \%$, as well as the proportion of malignant neoplasms of the respiratory system in the structure of all malignant neoplasms by $11,98 \%$.

2. Negative is the tendency to detect malignant neoplasms of the respiratory organs in the late stages.

3. The frequency of deaths of men from STIs exceeds the frequency among women, although among women the mortality rate increased by $16,38 \%$ within 5 years.

4. In general, the mortality rate from MT to 1 year from the moment of diagnosis is higher among men than among women. The same tendency is confirmed also about MT of respiratory organs.

\section{REFERENCES}

1. Fedorenko Z. P., Hulak L. 0., Mykhailovych Yu. Y. et al. Rak v Ukraini, 2015-2016 r. Zakhvoriuvanist, smertnist, pokaznyky diialnosti onkolohichnoi sluzhby [Cancer in Ukraine, 2015-2016 years. Morbidity, mortality, indicators of oncological service activity]. Bull. Nat. Cancer Registry of Ukraine. Kyiv. 2017;18: 130. (in Ukrainian).

2. Bray F., Jemal A., Grey N. et al. Global cancer transitions according to the Human Development Index (2008-2030): a population-based study. The Lancet Oncology. 2012;13:790-801.

3. Cruz D., Charles S., Lynn T. Et al. Lung Cancer: Epidemiology, Etiology, and Prevention. Clinics in Chest Medicine. 2011;32:605-44.

4. Qi W.-X., Wang Q., Jiang Y.-L. et al. Overall Survival Benefits for Combining Targeted Therapy as Second-Line Treatment for Advanced Non-Small-Cell-Lung Cancer: A Meta-Analysis of Published Data. PLOS ONE. 2013;8:1-9.

5. The National Lung Screening Trial Research Team. Reduced Lung-Cancer Mortality with Low-Dose Computed Tomographic Screening. The new england journal of medicine. 2011; 365(5):395-409.
6. Cassidy A., Duffy S.W., Myles J. P. et al. Lung cancer risk prediction: A tool for early detection. International Journal of Cancer. 2007;120:1-6.

7. Brenner D. R., Boffetta P., Duell E. J. et al. Previous lung diseases and lung cancer risk: A pooled analysis from the international lung cancer consortium. American Journal of Epidemiology. 2012; 176: 573-85.

8. Houghton A. Mechanistic links between COPD and lung cancer. Nature Reviews Cancer. 2013;13:233-45.

9. Denholm R., Schüz J., StraifK. et al. Is previous respiratory disease a risk factor for lung cancer? American Journal of Respiratory and Critical Care Medicine. 2014;190:549-59.

10. Marcus M. W., Chen Y., Raji O. Y. et al. LLPi: Liverpool Lung Project risk prediction model for lung cancer incidence. Cancer Prevention Research. 2015;8:570-5.

11. Varyvonchyk D. V., Edzhybiia 0. M., Isypova V. M. Skryninh ta rannia diahnostyka zloiakisnykh novoutvoren orhaniv dykhannia pid chas provedennia medychnykh ohiadiv pratsivnykiv kantserohennonebezpechnykh vyrobnytstv. Informatsiinyi lyst. [Screening and early diagnosis of malignant neoplasms of the respiratory system during medical examinations of workers in carcinogenic and hazardous industries. Information guideline]. National Academy of Medical Sciences of Ukraine. Kyiv; 2020; 2. (in Ukrainian).

12. Skoromokhova T.V. Suchasnyi stan problemy likuvannia khvorykh zi zloiakisnymy novoutvorenniamy verkhnikh dykhalnykh shliakhiv (ohliad literatury ta rezultaty vlasnykh doslidzhen) [The current state of the problem of treatment of patients with malignant neoplasms of the upper respiratory tract (literature review and the results of their own research)]. Clinical Oncology. 2017; 1(25). Doi: https://www. clinicaloncology.com.ua/article/18137/. (in Ukrainian).

The article is done within the complex research framework for "Research of geopolitical, sanitary-hygienic, ecological, medical-demographic and socio-economic features of the Transcarpathian region as factors of health care reform in the region» state registration number 0120 U100987

\section{ORCID and contributionship:}

Olga V. Feger: 0000-0002-7615-9347 A,B,C,D

Renata Yu. Pohoriliak: 0000-0002-7388-9969 C,D,E,F

\section{Conflict of interest:}

The Authors declare no conflict of interest.

\section{CORRESPONDING AUTHOR \\ Olga V. Feger \\ Uzhhorod National University \\ 14 University St., 88000 Uzhhorod, Ukraine \\ tel: +380663477665 \\ e-mail: olga.feger@uzhnu.edu.ua}

Received: 10.12 .2020

Accepted: 29.03 .2021

A - Work concept and design, B - Data collection and analysis, C - Responsibility for statistical analysis, D-Writing the article, $\mathbf{E}$-Critical review, $\mathbf{F}-$ Final approval of the article 